\title{
Design and Implementation of Software Development Information Management System
}

\author{
Xu Pei \\ Nan Chang Institute of Science \& Technology, Nanchang, 330108
}

Keywords: Computer; Software development; Information management

\begin{abstract}
Based on the rapid progress of information technology in our country, computer software development information management system also has achieved good results. However, the current computer software development information management system has not been perfected. In order to make it to fully form a convenient management mode and effectively improve the efficiency of computer software development information management, a series of designs and implementations of computer software development information management system shall be required. This paper discusses the implementation methods of computer software development information management system on the basis of analysis of the design points of computer software development information management system. It is expected that the research in this paper can help to improve the computer software development information management level.
\end{abstract}

\section{Introduction}

Now, when computer software development is approached, the overall maintenance measures shall be taken for the relevant information, and more maintenance measures shall be taken for the product information and development version in the process of entering the development stage. However, when the development and management for relevant software are implemented, the software designers shall make it to be combined with the original characteristics fully and effectively to effectively control the development cost of software and reduce the workload of software development to some extent. The design of computer software development information management system has always been an important topic in the field of computer software development. Therefore, this paper mainly studies and analyses the design and implementation of computer software development information management system to make it to be effectively developed and widely applied.

\section{System Requirements}

Analysis of Information Relationship for Software Development. Software development information often consists of different kinds of information. As a software development process based on the primary-secondary relationship tree, the automatic setup process shall be gradually realized combined with the basic calculation process of workload and the realization of requirements' effectiveness. Once the business requirements are gradually achieved, it is time for the technical requirements. For the dependency relationship between the requirements information, the different requirements shall be met combined with the business requirements as much as possible.

For good performance of business requirements and technical requirements, much attention shall be paid to the overall design of software function and the effective implementation of function program to gradually apply the technical requirements related to the design requirements of sub-business as much as possible.

Requirements for Software Development Information Management. There are both the projected workload and the actual workload in the workload information management stage for the requirements information management. This stage is a process of carrying out the human resources combined with the requirements allocation of the manager. For the business requirements, much attention shall be not only paid to the development of technology effectiveness but also paid to the 
final determination of knowledge management workload and the reasonable management of quality to carry out the standardized application of document. Combined with the actual business requirements, much attention shall be paid to the development of software workload effectiveness and the realization of application of knowledge management workload to ensure the quality of software.

\section{Architecture Design of Software Development Information Management System}

In the architecture design process of software development information management system, we need to be mindful of the layers of information management system. There are 5 main layers when XML technology is applied in the design process of information management system. The 5 main layers are involved in the design process of the software development information management system based on XML technology, which separately are user operation layer, application layer, core layer, business logic layer and data layer shown as in Fig. 1

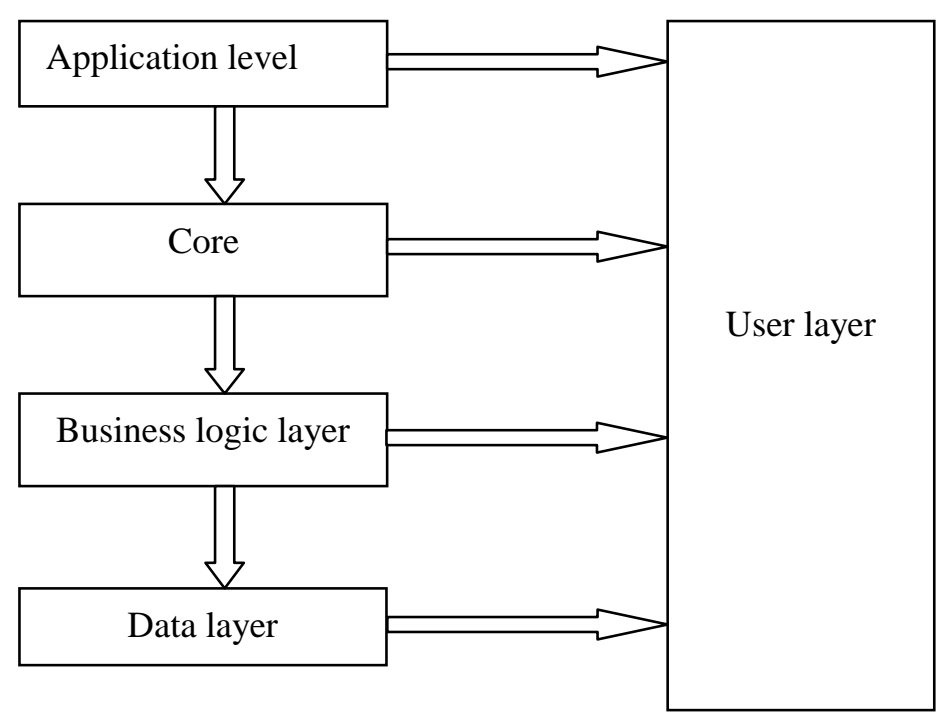

Figure 1. Design of Software Development Information Management System Based on XML Technology

Thereinto, the data layer mainly includes the relevant data information such as system data, definition data and business data; the business logic layer mainly involves the relevant business logic, data access and Web services; the core layer involves Addin tree, plug-in management and other services; the application layer mainly involves some content used to provide the relevant services for user such as privilege management, operating platform and interface definition; the user operation layer involves the relevant business system. For the design of software development information management system based on XML technology, much attention shall be paid to the performance of functions of all layers.

\section{System Flow}

The business requirements management system flow corresponding to the sequence of business requirements state is shown in Fig. 2

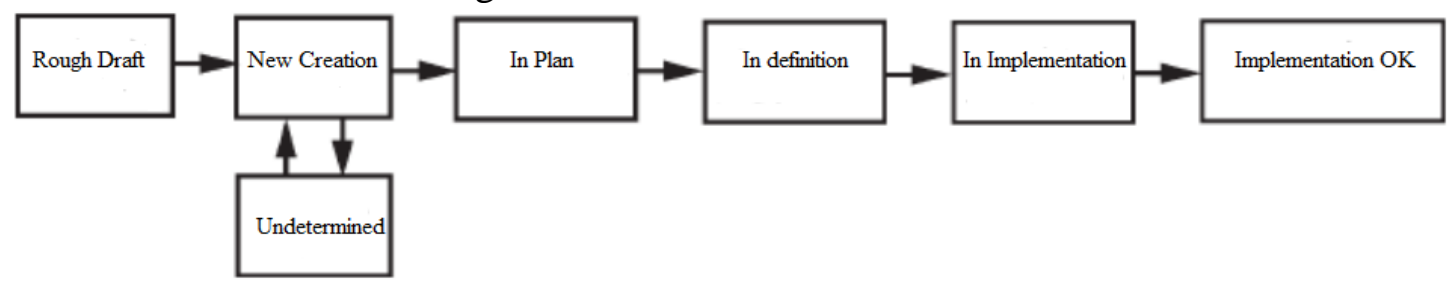

Figure 2. Sequence of System Business Requirements State 
When creating new business requirements, the relevant plan and definition shall be required for the implementation of system combined with the situation of business requirements.

The technical requirements management system flow is shown in Fig. 3.

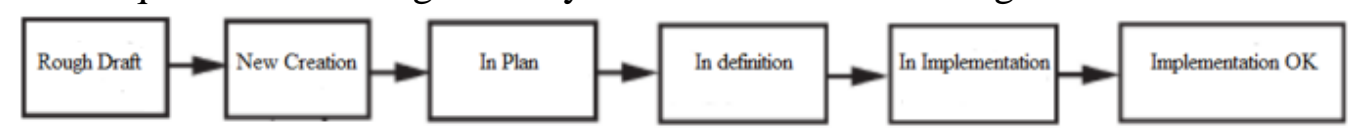

Figure 3. Technical Requirements Management System Flowchart

For the design of technical requirements management system, firstly, the creation work of rough draft shall be done well, and then the creation and plan shall be analyzed, lastly, the work of definition and implementation shall be finished well.

\section{Management and Design of Software Development Information Management System}

Design of Display and Information Query Module. Generally speaking, the display and information query module of system shall be designed on the basis of combination of product information and version release information, and which shall be displayed in the same interface to effectively apply the multilayer display mode and the level display mode. In general, the multilayer display mode is applied to display the system information in the unified interface to provide the relevant maintenance for the effectiveness of system product to a large extent in accordance with the effective combination of information. In addition, for analysis of the business requirements, the basic analysis for team development task shall be carried out only when the plan is formulated. However, in the basic development stage of system software, the level display mode has good performance in switching mode and realizing effective query of the relevant information for software development with the more advanced query application.

Design of Business Requirements Information Management Module. Basic information is generally refer to a property of business requirements. Its relevant analysis shall be carried out by taking effective measures corresponding to the ID situation of business requirements, and the relevant combination shall be achieved according to the overall situations of information founder to well solve the problem of modifying the date. Ordinarily, the business requirements shall be met by being feedback of the business requirements in the query panel and relevantly combining the query requirements. For information allocation of workload, the reasonable allocation of workload can be carried out by fully combining the basic form with the projected workload and finishing the allocation process of workload in accordance with the expected time as soon as possible. In addition, for the application of attachment information, it is mainly required to combine the attachment upload with the attachment download and ensure the reasonableness of information creation.

Design of Other Modules. For design of other modules, it is mainly needed to make the designs of version information and product artistic, realize design in accordance with the situations of information ID and name and combine with the form of fields to make the application of investment project information to be effectively analyzed. In additional, it is inevitable for the comprehensive design.

\section{Implementation of System Management Flow}

For the implementation of system information management flow, the management process of business requirements information is refer to a process of generating the standard function combined with the form of status field. Based on analysis of the special dependency relationship of business requirements, combined with the effectiveness treatment of business requirements information, the previous data information is locked, and which can not be modified. In the implementation stage of technical requirements information management flow, when setting the technical requirements, the function shall be invoked, and the status of matching business requirements shall be modified. In the loading stage of technical requirements, the matching business requirements shall be automatically detected, and the modification of priority shall be 
done.

\section{Conclusion}

In conclusion, the design of computer software development information management system can not only promote the development of management software industry but also change status of the traditional software development management. Thereinto, the full combination of the basic mode of cloud computer and the software development information management system plays an important role for the development of management software industry that cloud computer can help to effectively create management software solutions, fully promotes the development of modern technological revolution, has immeasurably great effect on the development of national economy and provides strong backing for the social competence. The design and implementation of software development information management system provide the practical guidance for the information management for computer software development.

\section{References}

[1] Song H Y, Yao H Z. Training Center Management information system development based on maticsoft.NET[J]. Information Technology, 2014.

[2] Cheng X, Qiu X X. Design and Implementation of a Software Automation Development Framework for Management Information System[J]. Advanced Materials Research, 2014, 989-994(4):4488-4492.

[3] Sun K, Liu J, Yan X. Design and Development Experience of Enhanced Environment Laboratory Information Management System[J]. Journal of Environmental Management College of China, 2015.

[4] Xu J, Huang Y, Deng N. DESIGN AND STUDY ON A REINSURANCE INFORMATION MANAGEMENT SYSTEM FOR INDIVIDUAL INSURANCE[J]. Computer Applications \& Software, 2014.

[5] Shahla Ghobadi. What drives knowledge sharing in software development teams: A literature review and classification framework[J]. Information \& Management, 2015, 52(1):82-97.

[6] Zhang,Cheng. The Design and Implementation of Corporate Human Resources Management Information System[J]. Advanced Materials Research, 2014, 998-999:1670-1673.

[7] Amano T, Horiuchi Y, Kawase T, et al. SOFTWARE DEVELOPMENT WORK ITEM MANAGEMENT SYSTEM:, US20140181791[P]. 2014.

[8] Kostyshyn O O. Development of the land resource management system in the context of geographic information software[J]. Balanced Nature Using, 2015, 4.

[9] Rodmunkong T, Wannapiroon P, Nilsook P. Development of Information Management Systems in accordance with the Thai Qualifications Framework for Higher Education via Cloud Computing[C]// International E-Learning Conference. 2015.

[10]Blazek P, Krejcar O, Jun D, et al. Development of Information and Management System for Laboratory Based on Open Source Licensed Software[C]// Iccci. 2016:377-387.

[11]Jing L I, Zhen-Yang G E. Design of Production Information Management System of Tea Plantation Based on SSH2[J]. Journal of Anhui Agricultural Sciences, 2016.

[12] Kautz K, Johansen T H, Uldahl A. The Perceived Impact of the Agile Development and Project Management Method Scrum on Process Transparency in Information Systems Development[J]. 2017. 